\title{
PEMENFAATAN SISTEM INFORMASI GEOGRAFIS UNTUK EVALUASI KEMAMPUAN LAHAN DAN ARAHAN PENGGUNAAN LAHAN DI KECAMATAN SAMIGALUH KABUPATEN KULON PROGO
}

\author{
Oleh: \\ Janu Eko Herwanto ${ }^{1}$, Agus Sudarsono ${ }^{2}$, Bambang Saeful Hadi ${ }^{2}$ \\ ${ }^{1}$ SMA Negeri 23 Bandung, djanoeko11@yahoo.com \\ 2 Jurusan Pendidikan Geografi UNY
}

\begin{abstract}
Abstrak
Tujuan penelitian ini mengetahui kelas kemampuan lahan, mengetahui agihan kelas kemampuan lahan dan menentukan arahan penggunaan lahan yang sesuai dengan kemampuan lahan di wilayah Kecamatan Samigaluh Kabupaten Kulon Progo Provinsi Daerah Istimewa Yogyakarta. Evaluasi kemampuan lahan menggunakan satuan unit lahan sebagai unit analisis evaluasi lahan untuk mengetahui kelas kemampuan lahan. Analisis kemampuan lahan dilakukan dengan metode pencocokan (matching) terhadap 16 varian satuan unit lahan hasil tumpangsusun (overlay) peta bentuk lahan, jenis tanah dan kemiringan lereng. Karakteristik lahan setiap satuan unit lahan diperoleh dari survei di lapangan dan analisis tanah di laboratorium. Arahan penggunaan lahan disesuaikan dengan kelas kemampuan lahan yang terbentuk di daerah penelitian. Hasil penelitian yang diperoleh, yaitu: (1) Wilayah Kecamatan Samigaluh terdapat tujuh kelas kemampuan lahan, yaitu: Kelas II-e, III-ew, IV-ew, VI-e, VI-es, VII-e dan VII-es; (2) Agihan kelas kemampuan lahan di wilayah Kecamatan Samigaluh, yaitu: Kelas II-e di Desa Purwoharjo dengan luas 19,273 $\mathrm{Ha}$ atau 0,28\% daerah penelitian, Kelas III-ew di Desa Purwoharjo dengan luas 10,639 $\mathrm{Ha}$ atau 0,16\% daerah penelitian, Kelas IV-ew di seluruh desa wilayah penelitian dengan luas $541,736 \mathrm{Ha}$ atau $8,01 \%$ daerah penelitian, Kelas VI-e di seluruh desa wilayah penelitian dengan luas $1.933,980 \mathrm{Ha}$ atau $28,59 \%$ daerah penelitian, Kelas VI-es di Desa Purwoharjo, Desa Sidoharjo, Desa Banjarsari, Desa Ngargosari, Desa Gerbosari serta Desa Kebonharjo dengan luas lahan sebesar 576,950 Ha atau 8,53\% daerah penelitian, Kelas VII-e di Desa Purwoharjo, Desa Sidoharjo, Desa Purwoharjo, Desa Ngargosari dan Desa Gerbosari dengan luas lahan 269,126 Ha atau 3,98\% daerah penelitian, dan Kelas VII-es di seluruh desa wilayah penelitian dengan luas keseluruhan 3.413,599 $\mathrm{Ha}$ atau 50,46\% daerah penelitian; dan (3) Arahan penggunaan lahan yang sesuai dengan kemampuan lahan di wilayah Kecamatan Samigaluh, yaitu Kelas II-e untuk pertanian intensif, Kelas III-ew untuk pertanian sedang, Kelas IV-ew untuk pertanian terbatas, Kelas VI-e dan VI-es untuk penggembalaan sedang, perkebunan dan hutan produksi, Kelas VI-e dan VII-es untuk penggembalaan terbatas dan hutan produksi terbatas.
\end{abstract}

Kata kunci: SIG, Evaluasi Kemampuan Lahan, Arahan Penggunaan Lahan. 


\title{
THE UTILIZATION OF GEOGRAPHIC INFORMATION SYSTEM TO EVALUATE THE ABILITY OF LAND AND DIRECTION OF USING LAND IN SAMIGALUH KULON PROGO
}

\begin{abstract}
$\underline{\text { Abstract }}$
This research aims to know the level of land capability, know agihan of the land capability level and know the direction of land usage which is appropriate with the land capability in the District of Samigaluh Kulon Progo, Yogyakarta Special Province. The evaluation on the ability of land usage employs land unit as the unit of analysis for land evaluation to determine the level of land capability. Land capability analysis was conducted using matching technique to 16 variant of land unit as a result of overlying landform maps, type of soil and type of slopes. The characteristics of each land unit were obtained from the field survey and soil analysis in the laboratory. The direction of land usage is suited with the land capability level which is formed in the research setting. The findings of the research are: (1) the regional district of Samigaluh has seven level of land capability, namely: II-E, III-ew, ew-IV, VI-e,-ice VI, VII and VII-es; (2) the agihan of land capability level in the district of Samigaluh, consists of: class II-e in the village with an area of 19.273 ha Purwoharjo or $0.28 \%$ of the research areas, class III-ew Purwoharjo village with an area of 10.639 ha or $0.16 \%$ of the research areas, Class IV-ew all villages in the area of research with 541.736 ha width or $8.01 \%$ of the research areas, Class VI-E in the entire village area of research with 1933.980 hectares width or $28.59 \%$ of the research areas, Class VI-ice Purwoharjo, Sidoharjo, Banjarsari, Ngargosari, the and Kebonharjo Gerbosari village with a land area of 576.950 ha or $8.53 \%$ of the research areas, Class VII-e Purwoharjo, Sidoharjo, Purwoharjo, and Ngargosari Gerbosari village with a land area of 269.126 ha or $3.98 \%$ the research areas, and Class VII-es throughout the village area of research with a total area of 3413.599 hectares or $50.46 \%$ of the research areas, and (3) the direction of land usage which suits with the land capability in the district of Samigaluh include Class II-E for intensive farming, Class III-ew for standard agriculture, Class IV-ew for limited agriculture, Class VI-E and VI-ice for medium grazing, plantation and forest production, Class VI- $e$ and VII-ice for limited grazing and limited production forest.
\end{abstract}

Keywords: GIS, land capability evaluation, direction of land usage.

\section{PENDAHULUAN}

Lahan merupakan sumberdaya pembangunan yang memiliki karakteristik unik, yaitu persebaran atau luas relatif tetap karena perubahan luas akibat proses alami (sedimentasi) dan proses artifisial (reklamasi) sangat kecil; dan memiliki sifat fisik (jenis batuan, kandungan mineral, topografi dan sebagainya) dengan kesesuaian dalam menampung kegiatan atau aktivitas masyarakat yang terus berkembang (Ahmad Hermanto Dardak, 2008: 34). Sumberdaya Lahan sangat penting untuk memenuhi segala kebutuhan hidup, sehingga dalam pengelolaan dan pemanfaatannya harus dilakukan dengan cermat dan harus sesuai dengan kemampuannya agar tidak mengurangi dayaguna lahan serta menurunkan kemampuan lahan. Namun pada kenyataaannya terjadi pemanfaatan sumberdaya lahan secara berlebihan tanpa memperhatikan ketersediaan sumberdaya lahan maupun dayadukung lingkungan yang terbatas sehingga menimbulkan kerusakan lahan atau tanah. 
Lahan merupakan sumberdaya alam yang tidak dapat diperbaharui, padahal jumlah manusia yang ingin menggunakan lahan terus menerus bertambah. Selain itu, meningkatnya kesejahteraan penduduk juga dapat meningkatkan kebutuhan akan lahan. Oleh karena kebutuhan lahan untuk berbagai sektor penggunaan meningkat, maka terjadilah konflik atau perebutan penggunaan lahan. Konflik penggunaan lahan terjadi karena adanya benturan kepentingan antar sektoral dan pembangunan oleh akibat pertambahan penduduk. Benturan kepentingan dari berbagai pihak yang terlibat biasanya tercermin dalam konflik-konflik penggunaan lahan dan air. Benturan-benturan kepentingan ini pada akhirnya akan menimbulkan berbagai masalah degradasi sumberdaya alam dan lingkungan hidup, seperti erosi tanah yang berat, sedimentasi sungai, banjir, tanah longsor, dan gangguan-gangguan terhadap kawasan hutan.

Salah satu wilayah Provinsi Daerah Istimewa Yogyakarta yang rawan mengalami permasalahan degradasi sumberdaya alam dan lingkungan hidup tersebut adalah Kecamatan Samigaluh yang merupakan bagian dari Kabupaten Kulon Progo. Kecamatan Samigaluh memiliki berbagai permasalahan yang berkaitan dengan perannya dalam mendukung fungsi kawasan budidaya pertanian, non pertanian maupun kawasan lindung. Seiring dengan perkembangan wilayah yang mengarah pada fungsi-fungsi tersebut, maka benturan pemanfaatan lahan sangat terasa di kawasan yang potensial-produktif maupun kawasan lindung. Hasil observasi lapangan di beberapa titik di wilayah Desa Purwoharjo, Desa Banjarsari dan Desa Kebonharjo menunjukkan terjadinya perubahan penggunaan lahan dari daerah yang seharusnya kawasan lindung atau kehutanan menjadi kawasan pertanian untuk menopang kebutuhan bahan makanan seperti padi, ubi-ubian, palawija, tanaman perkebunan, sayur, buah-buahan dan sebagainya. Berdasarkan hal tersebut dapat dilihat masalah utamanya adalah kurangnya perencanaan penggunaan lahan dan benturan kepentingan di berbagai sektor yang terkait dengan potensi lahan. Selain itu juga adanya variasi kondisi bentang lahan dari Kecamatan Samigaluh yang merupakan bentang lahan struktural denudasional Perbukitan Menoreh yang bertopografi kasar dengan lereng yang curam. Kondisi tersebut berpengaruh pada variasi kelas kemampuan lahan di suatu bentang lahan beserta penggunaan lahannya. Untuk mengatasi permasalahan yang berkaitan dengan perencanaan penggunaan lahan, kemampuan lahan dan konflik penggunaan lahan maka diperlukan evaluasi lahan dan perencanaan penggunaan lahan secara terpadu.

Pemanfaatan sumberdaya lahan yang tidak sesuai peruntukannya merupakan kesalahan dalam sistem tataguna lahan sehingga menurunkan kemampuan lahan di suatu wilayah. Hal tersebut ditunjukkan dengan indikator terjadinya erosi tanah yang berat, sedimentasi sungai, banjir, tanah longsor, dan gangguan-gangguan terhadap kawasan hutan di Kecamatan Samigaluh. Kondisi topografi Kecamatan Samigaluh yang berbukit dengan tingkat kemiringan lahan terjal memiliki luas cukup dominan (lihat Gambar 1) menyebabkan resiko erosi tanah yang berat. Sub DAS Tinalah merupakan kawasan penyangga dan catchment area bagi Daerah Aliran Sungai (DAS) Progo yang cukup penting di bagian utara Perbukitan Menoreh. Perubahan tataguna lahan di wilayah tersebut yang pemanfaatannya tidak sesuai dengan kemampuan lahan akan berdampak terhadap DAS Progo dan sekitarnya, contoh terjadinya kerusakan lahan pertanian, erosi tebing sungai (stream bank erosion), sedimentasi sungai dan banjir. 


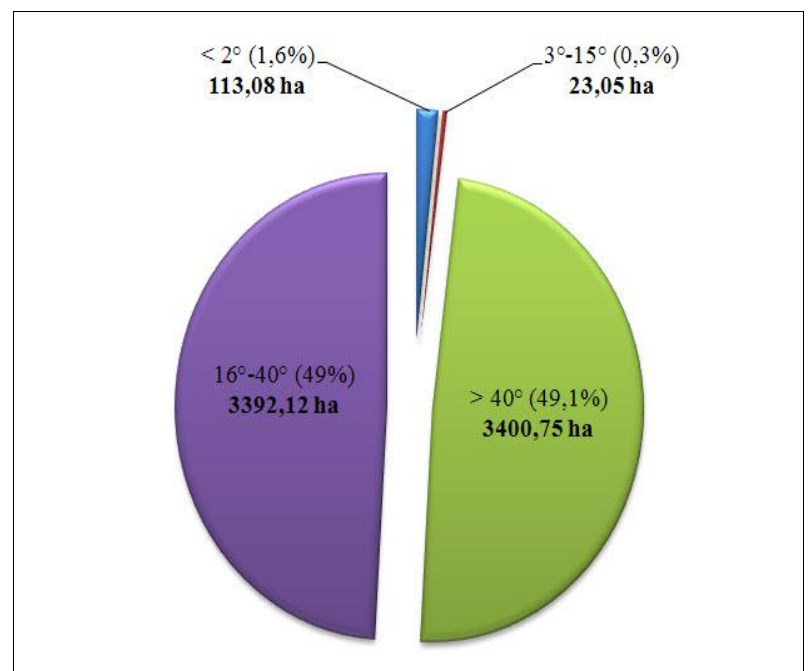

Gambar 1. Distribusi Luas Tanah Menurut Tingkat Kemiringan Lahan di Kecamatan Samigaluh

(Sumber: BPS Kabupaten Kulon Progo, 2009)

Pengelolaan dan pemanfaatan kawasan hutan yang kurang bijaksana juga menyebabkan terjadinya degradasi lahan dan gangguan fungsi hutan yang berimplikasi terhadap masalah sosial ekonomi, psikologis dan ekologis yang destruktif. Upaya rehabilitasi maupun konservasi lahan hutan akan mampu meningkatkan dan mempertahankan kemampuan lahan, sehingga dapat berfungsi dan berdayaguna secara optimal, baik sebagai unsur produksi maupun sebagai media pengatur tata air dan perlindungan lingkungan alam (Senawi, 2006: 138).

Kondisi topografi Kecamatan Samigaluh sebagian besar (98\%) memiliki kelerengan lebih dari $16^{\circ}$ tersebut (lihat Gambar 1 ) menyebabkan wilayah tersebut rawan mengalami kasus bencana alam tanah longsor. Contoh kasus yang pernah terjadi antara lain: tanah longsor yang terjadi pada tanggal 20 November 2001 di Dukuh Kedungrong, Desa Purwoharjo Kecamatan Samigaluh, mengakibatkan tujuh orang tewas, 13 rumah hancur, serta tiga rumah rusak. Musibah itu diawali hujan deras berkepanjangan yang diikuti banjir (Badan Koordinasi Nasional Penanggulangan Bencana, Rabu 8 November 2006); lokasi tanah longsor mencapai 24 titik kejadian pada tanggal 27 Desember 2007 di Desa Kebonharjo Kecamatan Samigaluh. Sebanyak 16 titik tanah longsor menimpa rumah penduduk dan delapan titik menimpa sarana jalan (Harian Kedaulatan Rakyat, Sabtu 29 Desember 2007); dan tanah longsor yang terjadi di Desa Purwoharjo, Kecamatan Samigaluh pada tanggal 20 Februari 2010, mengakibatkan jalan yang menghubungkan antara Kecamatan Samigaluh dan Kalibawang lumpuh total selama beberapa jam (Harian Suara Merdeka, Senin 22 Februari 2010).

Upaya untuk menghindari kesalahan dalam tataguna lahan dan dayaguna lahan serta mengatasi masalah turunnya kemampuan lahan, salah satu jalan adalah perencanaan penggunaan lahan yang sesuai dengan kemampuannya. Perencanaaan penggunaan lahan yang baik tidak terlepas dari tindakan evaluasi kemampuan lahan. Kerangka dasar dari evaluasi kemampuan lahan adalah membandingkan persyaratan tertentu dengan sifat-sifat lahan yang ada pada lahan tersebut. 
Penyusunan kebijakan dalam penggunaan lahan sangat memerlukan peta-peta sebagai media informasi yang salah satunya adalah peta kemampuan lahan. Analisis dan evaluasi kemampuan lahan dapat mendukung proses penyusunan rencana penggunaan lahan di suatu wilayah yang disusun dengan cepat dan tepat sebagai dasar pijakan dalam mengatasi benturan pemanfaatan penggunaan lahan atau sumberdaya alam. Oleh karena keterbatasan stakeholder pembangunan wilayah tentang informasi kelas kemampuan lahan secara lengkap dan akurat, serta penyediaan data spasial bereferensi geografi sehingga membutuhkan suatu penelitian untuk menghasilkan data dan informasi tentang klasifikasi kemampuan lahan di Kecamatan Samigaluh Kabupaten Kulon Progo secara spasial. Permasalahan yang terjadi saat ini adalah belum diketahuinya kelas kemampuan lahan dan persebaran atau agihan kemampuan lahan yang lengkap dan terbaru di Kecamatan Samigaluh. Oleh karena itu, arahan penggunaan lahan yang sesuai dengan kemampuan lahan di wilayah tersebut juga belum optimal. Informasi-informasi spasial tentang hal-hal tersebut juga belum memadai dalam bentuk peta kemampuan lahan dan peta arahan penggunaan lahan di wilayah Kecamatan Samigaluh, sehingga dibutuhkan suatu sistem informasi yang dapat mengolah dan menyajikan data-data spasial sumberdaya lahan secara terintegrasi. Sistem Informasi Geografis (SIG) dapat menghasilkan informasi klasifikasi kemampuan lahan terbaru yang lengkap, akurat dalam bentuk spasial digital. SIG mampu menyediakan informasi untuk mengatasi permasalahan kesenjangan informasi potensi sumberdaya alam untuk arahan perencanaan pembangunan berkelanjutan di wilayah penelitian.

\section{METODE PENELITIAN}

Penelitian ini dilakukan dengan menggunakan metode survei atau observasi, dokumentasi, dan uji laboratorium. Observasi dilakukan untuk melakukan penilaian dan pengukuran kondisi lapangan untuk mendapatkan data primer serta menguji ketelitian data-data di lapangan yang diperoleh dari instansi yang berkaitan maupun data sekunder lainnya. Penilaian langsung dilakukan untuk mendapatkan data primer di lapangan berupa: tingkat erosi, kelas drainase tanah, kerikil atau batuan, dan tingkat bahaya banjir. Pengukuran dilakukan untuk mengetahui data primer berupa tingkat kecuraman atau kemiringan lereng dan kelas kedalaman tanah atau kedalaman efektif tanah. Letak titik sampel penelitian juga dapat diketahui dengan menggunakan perangkat Global Positioning System (GPS). Melalui teknik dokumentasi juga diperoleh data sekunder yang terdapat di instansi-instansi yang berkaitan seperti BAPPEDA, BPN, BMKG, BPS, dan lainlain. Uji laboratorium dimaksudkan untuk memperoleh data primer tentang sifat-sifat fisik tanah yang meliputi: jenis tekstur tanah, nilai permeabilitas tanah, tingkat salinitas tanah dan kandungan $\mathrm{C}$ organik. Populasi penelitian ini adalah seluruh satuan unit lahan di Kecamatan Samigaluh Kabupaten Kulon Progo. Penentuan jumlah sampel menggunakan purposive area sampling dengan jumlah sampel yaitu 16 satuan unit lahan. Penentuan lokasi sampel uji ketelitian pemetaan menggunakan proportional sampling dengan jumlah lokasi sampel yaitu 36 titik sampel. Teknik analisis data yang digunakan yaitu uji ketelitian hasil interpretasi peta metode Short, analisis SIG metode tumpangsusun (overlay) dan analisis SIG metode pencocokan (matching). 


\section{HASIL DAN PEMBAHASAN}

\section{Karakteristik Lahan}

Karakteristik lahan di Kecamatan Samigaluh dapat diketahui melalui pengamatan maupun pengukuran sifat tanah, lereng, erosi dan banjir. Penilaian karakteristik lahan dilakukan terhadap sampel satuan unit lahan yang terbentuk dari hasil overlay terhadap kriteria-kriteria geofisik tertentu, yaitu bentuk lahan, jenis tanah dan kemiringan lereng. Gambaran karakteristik masing-masing satuan unit lahan hasil observasi, pengukuran, uji laboratorium dengan bantuan analisis SIG overlay dan matching dapat dilihat pada Tabel 3 berikut ini:

Tabel 3. Karakteristik Lahan di Kecamatan Samigaluh

\begin{tabular}{|c|c|c|c|c|c|c|c|c|c|c|c|c|}
\hline SUL & Luas (Ha) & KKR & KKE & KTE & KKT & KTT & KPT & KDT & KKB & KBG & KST & $\mathrm{KKL}$ \\
\hline L-DA-II & 19,273 & B & KE3 & e1 & $\mathrm{k} 1$ & $\mathrm{t} 3$ & P2 & $\mathrm{d} 2$ & b0 & $\mathrm{O} 1$ & g0 & II - e \\
\hline L-LAB-III & 10,639 & $\mathrm{C}$ & $\mathrm{KE} 4$ & e2 & $\mathrm{k} 2$ & $\mathrm{t} 4$ & $\mathrm{P} 4$ & $\mathrm{~d} 3$ & b1 & $\mathrm{O} 2$ & g0 & III - e, w \\
\hline L-LAB-IV & 75,995 & $\mathrm{D}$ & KE6 & e3 & $\mathrm{k} 2$ & $\mathrm{t} 3$ & P5 & $\mathrm{d} 4$ & b2 & $\mathrm{O} 3$ & g0 & IV - e, w \\
\hline L-LAB-V & 465,741 & $\mathrm{D}$ & KE6 & e3 & $\mathrm{k} 2$ & $\mathrm{t} 4$ & P3 & $\mathrm{d} 4$ & b2 & $\mathrm{O} 3$ & g0 & IV - e, w \\
\hline L-LAB-VI & 306,222 & $\mathrm{E}$ & KE6 & e4 & $\mathrm{k} 3$ & $\mathrm{t} 4$ & $\mathrm{P} 4$ & $\mathrm{~d} 1$ & b2 & $\mathrm{O} 0$ & g0 & VI - e \\
\hline L-BSK-IV & 358,665 & $\mathrm{E}$ & KE5 & e4 & $\mathrm{k} 3$ & $\mathrm{t} 3$ & P2 & $\mathrm{d} 2$ & b3 & $\mathrm{O} 0$ & g0 & $\mathrm{VI}-\mathrm{e}, \mathrm{s}$ \\
\hline L-BSK-V & 218,285 & $\mathrm{E}$ & KE5 & e4 & $\mathrm{k} 3$ & $\mathrm{t} 3$ & P3 & $\mathrm{d} 1$ & b3 & $\mathrm{O} 0$ & g0 & VI - e, s \\
\hline L-BSK-VI & 255,001 & $\mathrm{~F}$ & KE5 & e5 & $\mathrm{k} 3$ & $\mathrm{t} 4$ & P3 & $\mathrm{d} 1$ & b3 & $\mathrm{O} 0$ & g0 & VII - e, s \\
\hline L-PD-IV & 811,415 & $\mathrm{E}$ & KE6 & e4 & $\mathrm{k} 3$ & $\mathrm{t} 4$ & P3 & $\mathrm{d} 2$ & b2 & $\mathrm{O} 0$ & g0 & $\mathrm{VI}-\mathrm{e}$ \\
\hline L-PD-V & 816,343 & $\mathrm{E}$ & KE5 & e4 & $\mathrm{k} 3$ & $\mathrm{t} 3$ & $\mathrm{P} 4$ & $\mathrm{~d} 1$ & b2 & $\mathrm{O} 0$ & g0 & VI - e \\
\hline L-PD-VI & 1909,478 & $\mathrm{~F}$ & KE6 & e5 & $\mathrm{k} 2$ & $\mathrm{t} 4$ & $\mathrm{P} 1$ & $\mathrm{~d} 3$ & b1 & $\mathrm{O} 0$ & g0 & VII - e, s \\
\hline L-KK-VI & 26,960 & $\mathrm{~F}$ & KE6 & e5 & $\mathrm{k} 2$ & $\mathrm{t} 4$ & P5 & $\mathrm{d} 2$ & b2 & $\mathrm{O} 0$ & g0 & VII - e \\
\hline L-LR-VI & 163,067 & $\mathrm{~F}$ & KE6 & e5 & $\mathrm{k} 3$ & $\mathrm{t} 4$ & $\mathrm{P} 4$ & $\mathrm{~d} 0$ & b3 & $\mathrm{O} 0$ & g0 & VII - e, s \\
\hline L-PS-IV & 146,353 & $\mathrm{~F}$ & KE6 & e5 & $\mathrm{k} 1$ & $\mathrm{t} 2$ & $\mathrm{P} 2$ & $\mathrm{~d} 2$ & $\mathrm{~b} 1$ & $\mathrm{O} 0$ & g0 & VII - e \\
\hline L-PS-V & 95,812 & $\mathrm{~F}$ & KE6 & e5 & $\mathrm{k} 2$ & $\mathrm{t} 4$ & P3 & $\mathrm{d} 2$ & b1 & $\mathrm{O} 0$ & g0 & VII - e \\
\hline L-PS-VI & 1086,053 & $\mathrm{~F}$ & KE6 & e5 & $\mathrm{k} 2$ & $\mathrm{t} 2$ & P2 & $\mathrm{d} 3$ & b1 & $\mathrm{O} 0$ & g0 & VII - e, s \\
\hline
\end{tabular}

Sumber: Hasil observasi, pengukuran, uji laboratorium dengan bantuan analisis SIG overlay dan matching

Keterangan:

SUL = Satuan Unit Lahan

$\mathrm{KKR}=$ Kelas Kemiringan Lereng

KKE $=$ Kelas Kepekaan Erosi Tanah

$\mathrm{KTE}=$ Kelas Tingkat Erosi

KKT $=$ Kelas Kedalaman Efektif Tanah

KTT $=$ Kelas Tekstur Tanah

KPT $=$ Kelas Permeabilitas Tanah

KDT = Kelas Drainase Tanah

$\mathrm{KKB}=$ Kelas Kerikil Batuan

$\mathrm{KBG}=$ Kelas Banjir/Genangan

KST = Kelas Salinitas Tanah

$\mathrm{KKL}=$ Kelas Kemampuan Lahan

\section{Kelas Kemampuan Lahan dan Agihan Kelas Kemampuan Lahan}

Kelas kemampuan lahan di Kecamatan Samigaluh berdasar Tabel 4, didominasi oleh kelas kemampuan lahan VI dan VII, dengan berbagai macam faktor pembatas yaitu kepekaan erosi atau tingkat erosi, drainase buruk, dan hambatan 
daerah perakaran (kedalaman tanah dangkal dan banyak kerikil batuan). Kelas kemampuan lahan ini umumnya terdapat di daerah-daerah dengan kemiringan lereng tinggi yang memiliki kepekaan erosi tinggi serta faktor-faktor fisik lain yang menyebabkan kondisi kualitas lahan menurun. Faktor penghambat permanen seperti kemiringan lereng sulit untuk dirubah, kecuali dengan melakukan tindakan konservasi lahan mekanik. Tindakan konservasi lahan belum tentu merubah kelas lahan tersebut, namun hanya mampu menaikkan atau menurunkan kelas kemampuan lahan suatu daerah untuk penggunaan tertentu. Kelas kemampuan lahan di Kecamatan Samigaluh beserta agihan atau persebaran lahannya dapat dilihat pada Tabel 4 berikut ini:

Tabel 4. Klasifikasi Kemampuan Lahan di Kecamatan Samigaluh

\begin{tabular}{|c|c|c|c|c|}
\hline Sampel & $\begin{array}{c}\text { Satuan } \\
\text { Unit } \\
\text { Lahan }\end{array}$ & $\begin{array}{c}\text { Kelas } \\
\text { Kemampuan } \\
\text { Lahan }\end{array}$ & Luas (Ha) & $\begin{array}{c}\text { Persentase } \\
(\%)\end{array}$ \\
\hline Sampel 1 & L-DA-II & II - e & 19,273 & 0,28 \\
\hline Sampel 2 & L-PD-V & VI - e & 816,343 & 12,07 \\
\hline Sampel 3 & L-LAB-V & IV - e, w & 465,741 & 6,88 \\
\hline Sampel 4 & L-BKS-VI & VII - e, s & 255,001 & 3,77 \\
\hline Sampel 5 & L-PS-VI & VII - e, s & 1086,053 & 16,05 \\
\hline Sampel 6 & L-PD-VI & VII - e, s & 1909,478 & 28,22 \\
\hline Sampel 8 & L-LAB-VI & VI - e & 306,222 & 4,53 \\
\hline Sampel 9 & L-LR-VI & VII - e, s & 163,067 & 2,41 \\
\hline Sampel 10 & L-KK-VI & VII - e & 26,960 & 0,40 \\
\hline Sampel 11 & L-LAB-III & III - e, w & 10,639 & 0,16 \\
\hline Sampel 13 & L-BSK-IV & VI - e, s & 358,665 & 5,30 \\
\hline Sampel 14 & L-PS-IV & VII - e & 146,353 & 2,16 \\
\hline Sampel 15 & L-PD-IV & VI - e & 811,415 & 11,99 \\
\hline Sampel 16 & L-LAB-IV & IV - e, w & 75,995 & 1,12 \\
\hline Sampel 17 & L-BSK-V & VI - e, s & 218,285 & 3,23 \\
\hline Sampel 18 & L-PS-V & VII - e & 95,812 & 1,42 \\
\hline & Jumlah & & 6764,322 & 100,00 \\
\hline
\end{tabular}

Sumber: Hasil Analisa dan Perhitungan, 2010

\section{Arahan Penggunaan Lahan}

Arahan penggunaan lahan yang sesuai dengan kemampuan lahan menunjukkan rekomendasi penggunaan lahan terhadap satuan unit lahan yang sudah diketahui kelas kemampuan lahannya, sehingga lahan tersebut dapat dimanfaatkan secara optimal dan lestari. Arahan penggunaan lahan kelas lahan I sampai IV memiliki kemampuan lahan untuk pengusahaan tanaman pertanian, 
sedangkan kelas lahan V sampai VIII tidak sesuai untuk budidaya pertanian karena memiliki faktor pembatas yang berat maupun permanen.

Wilayah permukiman yang berada pada kelas lahan V sampai VII sebaiknya melakukan upaya konservasi lahan yang berat untuk menghindari degradasi lahan maupun memperkecil resiko bahaya longsor lahan. Perluasan zona permukiman di kelas-kelas lahan tersebut seharusnya dibatasi karena kondisi lahan yang kurang sesuai. Pengusahaan pertanian pada lahan dengan kemampuan lahan yang kurang sesuai untuk budidaya pertanian (kelas V - VIII) biasanya dengan sistem tegalan dan sawah tadah hujan memerlukan usaha konservasi yang berat agar tingkat erosi lahan dan resiko longsor lahan dapat diperkecil.

Arahan penggunaan lahan berimplikasi terhadap penggunaan lahan potensial. Kesesuaian penggunaan lahan dapat diketahui dengan membandingkan antara penggunaan lahan potensial dengan penggunaan lahan aktual hasil interpretasi peta sumber. Arahan penggunaan lahan dihasilkan dari analisa kelas kemampuan lahan dari setiap unit lahan seperti pada Tabel 5 berikut ini:

Tabel 5. Arahan Penggunaan Lahan di Kecamatan Samigaluh

\begin{tabular}{|c|c|c|c|c|}
\hline $\begin{array}{c}\text { Satuan } \\
\text { Unit } \\
\text { Lahan }\end{array}$ & $\begin{array}{c}\text { Kelas } \\
\text { Kemampuan } \\
\text { Lahan } \\
\end{array}$ & $\begin{array}{c}\text { Arahan } \\
\text { Penggunaan } \\
\text { Lahan } \\
\end{array}$ & Penggunaan Lahan Aktual & Keterangan \\
\hline L-DA-II & II - e & Pertanian Intensif & $\begin{array}{l}\text { Permukiman, Sawah irigasi, } \\
\text { Sawah tadah hujan, } \\
\text { Tegalan, Kebun campuran. }\end{array}$ & Sesuai \\
\hline L-PD-V & VI - e & $\begin{array}{l}\text { Penggembalaan } \\
\text { Sedang, Kebun } \\
\text { Campuran, Hutan } \\
\text { Produksi } \\
\end{array}$ & $\begin{array}{l}\text { Permukiman, Sawah tadah } \\
\text { hujan, Tegalan, Kebun } \\
\text { campuran. }\end{array}$ & $\begin{array}{l}\text { Permukiman } \\
\text { dibatasi, Pertanian } \\
\text { dengan konservasi } \\
\text { lahan berat }\end{array}$ \\
\hline L-LAB-V & IV - e, w & Pertanian Terbatas & $\begin{array}{l}\text { Permukiman, Sawah irigasi, } \\
\text { Sawah tadah hujan, } \\
\text { Tegalan, Kebun campuran. }\end{array}$ & $\begin{array}{l}\text { Pertanian dengan } \\
\text { konservasi lahan } \\
\text { ringan }\end{array}$ \\
\hline L-BSK-VI & VII - e, s & $\begin{array}{l}\text { Penggembalaan } \\
\text { Terbatas, Hutan } \\
\text { Produksi Terbatas }\end{array}$ & $\begin{array}{l}\text { Permukiman, Sawah irigasi, } \\
\text { Sawah tadah hujan, } \\
\text { Tegalan, Kebun campuran, } \\
\text { Belukar. }\end{array}$ & $\begin{array}{l}\text { Permukiman } \\
\text { kurang sesuai, } \\
\text { Pertanian dengan } \\
\text { konservasi lahan } \\
\text { berat }\end{array}$ \\
\hline L-PS-VI & VII - e, s & $\begin{array}{l}\text { Penggembalaan } \\
\text { Terbatas, Hutan } \\
\text { Produksi Terbatas }\end{array}$ & $\begin{array}{l}\text { Permukiman, Sawah tadah } \\
\text { hujan, Tegalan, Kebun } \\
\text { campuran, Belukar. }\end{array}$ & $\begin{array}{l}\text { Permukiman } \\
\text { kurang sesuai, } \\
\text { Pertanian dengan } \\
\text { konservasi lahan } \\
\text { berat } \\
\end{array}$ \\
\hline L-PD-VI & VII - e, s & $\begin{array}{l}\text { Penggembalaan } \\
\text { Terbatas, Hutan } \\
\text { Produksi Terbatas }\end{array}$ & $\begin{array}{l}\text { Permukiman, Sawah irigasi, } \\
\text { Sawah tadah hujan, } \\
\text { Tegalan, Kebun campuran, } \\
\text { Belukar. }\end{array}$ & $\begin{array}{l}\text { Permukiman } \\
\text { kurang sesuai, } \\
\text { Pertanian dengan } \\
\text { konservasi lahan } \\
\text { berat }\end{array}$ \\
\hline L-LAB-VI & VI - e & $\begin{array}{l}\text { Penggembalaan } \\
\text { Sedang, Kebun } \\
\text { Campuran, Hutan } \\
\text { Produksi }\end{array}$ & $\begin{array}{l}\text { Permukiman, Sawah irigasi, } \\
\text { Sawah tadah hujan, } \\
\text { Tegalan, Kebun campuran, } \\
\text { Belukar }\end{array}$ & $\begin{array}{l}\text { Permukiman } \\
\text { dibatasi, Pertanian } \\
\text { dengan konservasi } \\
\text { lahan berat }\end{array}$ \\
\hline L-LR-VI & VII - e, s & Penggembalaan & Permukiman, Sawah irigasi, & Permukiman \\
\hline
\end{tabular}




\begin{tabular}{|c|c|c|c|c|}
\hline & & $\begin{array}{l}\text { Terbatas, Hutan } \\
\text { Produksi Terbatas }\end{array}$ & $\begin{array}{l}\text { Sawah tadah hujan, } \\
\text { Tegalan, Kebun campuran. }\end{array}$ & $\begin{array}{l}\text { kurang sesuai, } \\
\text { Pertanian dengan } \\
\text { konservasi lahan } \\
\text { berat }\end{array}$ \\
\hline L-KK-VI & VII - e & $\begin{array}{l}\text { Penggembalaan } \\
\text { Terbatas, Hutan } \\
\text { Produksi Terbatas }\end{array}$ & $\begin{array}{l}\text { Permukiman, Sawah irigasi, } \\
\text { Sawah tadah hujan, } \\
\text { Tegalan, Kebun campuran. }\end{array}$ & $\begin{array}{l}\text { Permukiman } \\
\text { kurang sesuai, } \\
\text { Pertanian dengan } \\
\text { konservasi lahan } \\
\text { berat }\end{array}$ \\
\hline L-LAB-III & III - e, w & Pertanian Sedang & $\begin{array}{l}\text { Permukiman, Sawah tadah } \\
\text { hujan, Tegalan, Kebun } \\
\text { campuran. }\end{array}$ & Sesuai \\
\hline L-BSK-IV & VI - e, s & $\begin{array}{l}\text { Penggembalaan } \\
\text { Sedang, Kebun } \\
\text { Campuran, Hutan } \\
\text { Produksi }\end{array}$ & $\begin{array}{l}\text { Permukiman, Sawah tadah } \\
\text { hujan, Tegalan, Kebun } \\
\text { campuran, Belukar. }\end{array}$ & $\begin{array}{l}\text { Permukiman } \\
\text { dibatasi, Pertanian } \\
\text { dengan konservasi } \\
\text { lahan berat }\end{array}$ \\
\hline L-PS-IV & VII - e & $\begin{array}{l}\text { Penggembalaan } \\
\text { Terbatas, Hutan } \\
\text { Produksi Terbatas }\end{array}$ & $\begin{array}{l}\text { Permukiman, Sawah tadah } \\
\text { hujan, Tegalan, Kebun } \\
\text { campuran. }\end{array}$ & $\begin{array}{l}\text { Permukiman } \\
\text { kurang sesuai, } \\
\text { Pertanian dengan } \\
\text { konservasi lahan } \\
\text { berat }\end{array}$ \\
\hline L-PD-IV & VI - e & $\begin{array}{l}\text { Penggembalaan } \\
\text { Sedang, Kebun } \\
\text { Campuran, Hutan } \\
\text { Produksi }\end{array}$ & $\begin{array}{l}\text { Permukiman, Sawah irigasi, } \\
\text { Sawah tadah hujan, } \\
\text { Tegalan, Kebun campuran. }\end{array}$ & $\begin{array}{l}\text { Permukiman } \\
\text { dibatasi, Pertanian } \\
\text { dengan konservasi } \\
\text { lahan berat }\end{array}$ \\
\hline L-LAB-IV & IV - e, w & Pertanian Terbatas & $\begin{array}{l}\text { Permukiman, Sawah tadah } \\
\text { hujan, Tegalan, Kebun } \\
\text { campuran. }\end{array}$ & $\begin{array}{l}\text { Pertanian dengan } \\
\text { konservasi lahan } \\
\text { ringan }\end{array}$ \\
\hline L-BSK-V & $V I-e, s$ & $\begin{array}{l}\text { Penggembalaan } \\
\text { Sedang, Kebun } \\
\text { Campuran, Hutan } \\
\text { Produksi }\end{array}$ & $\begin{array}{l}\text { Permukiman, Sawah irigasi, } \\
\text { Sawah tadah hujan, } \\
\text { Tegalan, Kebun campuran, } \\
\text { Belukar. }\end{array}$ & $\begin{array}{l}\text { Permukiman } \\
\text { dibatasi, Pertanian } \\
\text { dengan konservasi } \\
\text { lahan berat }\end{array}$ \\
\hline L-PS-V & VII - e & $\begin{array}{l}\text { Penggembalaan } \\
\text { Terbatas, Hutan } \\
\text { Produksi Terbatas }\end{array}$ & $\begin{array}{l}\text { Permukiman, Sawah tadah } \\
\text { hujan, Tegalan, Kebun } \\
\text { campuran. }\end{array}$ & $\begin{array}{l}\text { Permukiman } \\
\text { kurang sesuai, } \\
\text { Pertanian dengan } \\
\text { konservasi lahan } \\
\text { berat }\end{array}$ \\
\hline
\end{tabular}

Sumber: Hasil Analisa dan Perhitungan, 2010

\section{KESIMPULAN}

Kelas kemampuan lahan II - IV merupakan lahan yang potensial untuk budidaya pertanian yang meliputi satuan unit lahan: Kelas II-e di Desa Purwoharjo dengan luas 19,273 $\mathrm{Ha}$ atau 0,28\% daerah penelitian; Kelas III-ew di Desa Purwoharjo dengan luas 10,639 Ha atau 0,16\% daerah penelitian; dan Kelas IV-ew di seluruh desa wilayah penelitian dengan luas $541,736 \mathrm{Ha}$ atau $8,01 \%$ daerah penelitian. Kelas kemampuan lahan VI - VII merupakan lahan yang potensial untuk penggunaan penggembalaan, perkebunan, hutan produksi terbatas. Arahan perencanaan secara umum di daerah penelitian dapat diaplikasikan untuk fungsi kawasan budidaya maupun lindung.

\section{SARAN}


Bagi pemerintah perlu melalukan perencanaan atau arahan penggunaan lahan dengan pendekatan kemampuan lahan untuk menuju pembangunan kawasan perdesaan yang berbasis pertanian serta pencanangan program khusus berbasis pembangunan perkebunan maupun kehutanan yang berorientasikan kesejahteraan masyarakat dan pelestarian lingkungan. Bagi petani digalakkan partisipasi aktif dalam usaha konservasi lahan dan perlindungan tanah - air untuk menghindari degradasi lahan, ancaman erosi tanah serta menerapkan upaya mitigasi bencana alam. Bagi penyuluh pertanian melaksanakan sosialisasi upaya konservasi lahan terhadap lahan pertanian, perkebunan dan kehutanan secara komprehensif dan informatif dan memberikan arahan pengembangan komoditas pertanian dan perkebunan yang prospektif dan bernilai ekonomis tinggi yang sesuai dengan kemampuan lahannya.

\section{DAFTAR PUSTAKA}

Ahmad Hermanto Dardak, Sitanala Arsyad dan Ernan Rustiadi. 2008. Penyelamatan Tanah, Air dan Lingkungan. Bogor: Yayasan Obor Indonesia.

Badan Pusat Statistik Kabupaten Kulonprogo. 2009. Kabupaten Kulonprogo dalam Angka 2008. Badan Pusat Statistik Kabupaten Kulonprogo. 2009. Kecamatan Samigaluh dalam Angka 2008. Badan Pusat Statistik Kabupaten Kulonprogo.

Buckman, Harry O. dan Brady, Nyle C.. 1982. Ilmu Tanah (Soegiman. Terjemahan). Jakarta: Bhratara Karya Aksara. Buku asli diterbitkan tahun 1969.

Dent, David dan Young, Anthony. 1981. Soil Survey and Land Evaluation. Sydney: George Allen and UNWIN.

Senawi. 2006. Analisis Kemampuan dan Daya Dukung Lahan untuk Penatagunaan Lahan Sub DAS Dengkeng DAS Bengawan Solo. Yogyakarta: Majalah Geografi Indonesia Vol. 20 N0. 2, September 2006 Halaman 137-151.

Sitanala Arsyad. 2010. Konservasi Tanah dan Air: Edisi Kedua. Bogor: Penerbit IPB Press.

Wartono Raharjo, dkk. 1977. Peta Geologi Lembar Yogyakarta, Jawa. Bandung: Direktorat Geologi Departemen Pertambangan. 